\section{SURVEY REVEALS CARIES KNOWLEDGE GAP}

New data published by the Oral Health Foundation and Colgate-Palmolive has discovered a concerning lack of knowledge of dental caries among patients. ${ }^{1}$ The Oral Health Foundation is now calling on dental professionals to help raise awareness of dental caries amongst patients in order to improve the oral health of the nation.

Dental caries is estimated to affect around 2.3 billion people globally. ${ }^{2}$ In the UK, it is estimated that just under one-in-three adults suffer from caries ${ }^{3}$ - a problem which the charity believes has been exacerbated during the pandemic.

Despite its prevalence, many patients remain unaware of the circumstances that could lead to them being at higher risk or understand how they can prevent the disease from occurring.

As part of a new nationwide omnibus survey into dental caries and fluoride [sample size $=2,008$, one-in-three $(33 \%)$ were unable to identify 'brushing teeth' as an action that could prevent the disease.

Furthermore, over half of respondents (54\%) did not associate 'regular dental appointments' to lower caries risk while and more than one-in-four (26\%) did not know that 'high carbohydrate' diets can be responsible for higher caries risk. ${ }^{3}$

There was also a lack of awareness around the other major risk factors of caries, including older age, dry mouth, and having a history of oral health restorations.

The survey's findings are part of the Oral Health Foundation's The Truth About Tooth Decay - an online hub, created in partnership with Colgate-Palmolive. The platform hosts educational material for patients around dental caries. The site also includes a dedicated area for dental professionals with tips and tools for educating patients about the symptoms and risk factors of dental caries.

Dr Ben Atkins, President of the Oral Health Foundation, believes the results of this survey have highlighted a knowledge gap that needs to be addressed sooner rather than later.

Dr Atkins said: 'Dental professionals are in a great position to help patients of all ages better understand their oral health. This education cannot only be done in the dental chair, it can also be done digitally on social media and through e-communications. The latter has become increasingly important given the restrictions from the pandemic. Digital learning is likely to play a key role in delivering the prevention aspects of the new dental contract'.

For more information, and to view The Truth About Tooth Decay online hub, visit www.dentalhealth.org/ thetruthabouttoothdecay.

\section{References}

1. Oral Health Foundation and ColgatePalmolive. Dental Caries Awareness Survey. UK: Broadcast Revolution, 2021.

2. World Health Organization. Sugar and dental caries. 2017. Available at: https://www.who.int/oral_health/ publications/sugars-dental-caries-keyfacts/ en/\#:\%7E:text=It\%20is\%20also\%20the\%20 most,by\%20avoiding\%20dietary\%20 free\%20sugars (accessed 28 May 2021).

3. NHS. The Information Centre for health and social care. 2. Disease and related disorders - a report from the Adult Dental Health Survey 2009. 24 March 2011. Available at: https://files.digital.nhs.uk/ publicationimport/pub01xxx/pub01086/ adul-dent-heal-surv-summ-them-the22009-rep4.pdf (accessed 28 May 2021).

\title{
GROWING POSITIVITY FOR WATER FLUORIDATION ON SOCIAL MEDIA
}

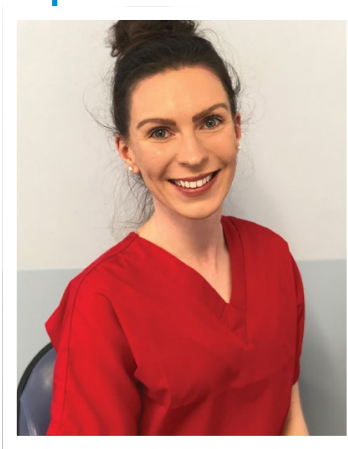

fluoridation has remained constant.

These are among the conclusions drawn from a paper ${ }^{1}$ which compares identical studies analysing social media accounts on Twitter and Facebook. Carried out five years apart, in 2015 and 2021, the studies looked at the public's perception of water fluoridation as expressed on social media. Accounts were divided into three groups: supportive, ante or neutral to water fluoridation.

Water fluoridation is a topic which invokes strong feelings, with libertarians opposing the view that fluoride should be added to drinking water supplies alongside other chemicals that prevent disease, such as chlorine, which protects from cholera and typhoid. This is counter to the view of most healthcare organisations, especially dental, which support all measures designed to improve health through universal measures.

British Fluoridation Society (BFS) member Rebecca Linney (pictured) undertook the 2015 study as part of her dental degree to understand how social media was being used by campaigners. Dr Linney was fascinated by the topic because she comes from Liverpool where the water is not fluoridated but undertook her dental degree in fluoridated Birmingham.

In March of this year she repeated the study to test whether there had been a change in perceptions. A key finding of her comparison is that today, $19 \%$ of Twitter accounts featuring water fluoridation support the public health measure whereas in 2015 there were no pro-water fluoridation accounts at all.
Barry Cockcroft, Chairman of BFS, said: 'This paper is really useful in understanding how important it is to continue to communicate clear and scientific statements about water fluoridation. The fact is, unless we keep active on social media, opponents will fill that vacuum. This is a most valuable piece of work'.

\section{Reference}

1. Linney R. A comparison of the public's perception of water fluoridation based on social media posts between June 2015 and March 2021. May 2021. Available at: https://bfsweb.org/wp-content/ uploads/2021/05/rebecca-linney-Acomparison-of-the-publics-perceptionof-Water-Fluoridation-based-on-socialmedia-posts-between-June-2015-andMarch-2021.pdf (accessed May 2021). 